\title{
COMPARISON OF CANAL TRANSPORTATION AND CENTERING ABILITY OF XP SHAPER, WAVEONE AND ONESHAPE: A CONE BEAM COMPUTED TOMOGRAPHY STUDY OF CURVED ROOT CANALS
}

\author{
Reham Hassan*, Nehal Roshdy ${ }^{* *}$ and Noha Issa***
}

\begin{abstract}
This study investigated the shaping abilities of XP Shaper and compared it with other single file NiTi systems using full rotation and reciprocation motion by cone beam computed tomography. Mesiobuccal canal of forty-five mandibular first molars, were divided into three equal groups, using WaveOne, OneShape and XP shaper. Pre-and post instrumentation images were obtained at $3 \mathrm{~mm}$, $5 \mathrm{~mm}$ and $7 \mathrm{~mm}$ from the apex and were assessed to determine canal transportation and centering ability. Data were analyzed using Kruskal-Wallis test for comparing the three systems, while Friedman's test was used to compare between the root levels. WaveOne and OneShape showed the highest mean amount of transportation with no statistically significant difference between them. XP Shaper showed the lowest statistically significantly mean amount of transportation. There was a statistically significant difference in the canal centring ability among the three instruments used. It was concluded that XP shaper preserved the original canal shape better than WaveOne and OneShape.
\end{abstract}

KEYWORDS: Canal transportation, Centering ability, Cone beam computed tomography, OneShape, WaveOne, XP Shaper.

\section{INTRODUCTION}

The ultimate root canal treatment goal is the removal of infected pulpal remnants, elimination of microorganisms, shaping of the root canal system through optimum biomechanical preparation ${ }^{(1)}$. Root canals should be uniformly enlarged in all dimensions to permit thorough disinfection while maintaining the original curvature without introducing iatrogenic errors ${ }^{(2)}$.

However, endodontic preparation in narrow and curved root canals has always been a challenge, due to the tendency of the prepared canal to deviate from its natural axis ${ }^{(3)}$. Continuous innovations and techniques are being established aiming to reduce the difficulties encountered during endodontic therapy. The use of nickel-titanium instruments allowed for a

\footnotetext{
* Department of Endodontics, Faculty of Dentistry, Minia University.

** Department of Endodontics, Faculty of Dentistry, Cairo University.

*** Oral and Maxillofacial Radiology Department, Faculty of Dentistry, Cairo University.
} 
favorable treatment of curved canals in shorter time through their enhanced properties of shape memory, super elasticity and cutting efficiency (4).

Various single-file systems with different metallurgy and designs have been promoted to prepare root canals with one instrument using either continuous rotation or reciprocation motion. WaveOne (Dentsply Maillefer, Ballaigues, Switzerland) and OneShape (Micro Mega, Besancon, France) are representatives for these single file systems. Where, Waveone works in reciprocation motion and are made of a special NiTi-alloy called M-Wire which is created by an innovative thermal treatment process. The benefits of this M-Wire NiTi are based on increased flexibility of the instruments and on improvement of resistance to cyclic fatigue, The Primary WaveOne file have a fixed tapers of $8 \%$ from D1-D3, whereas from D4-D16, they have a unique progressively decreasing percentage tapered design. This design serves to improve flexibility and conserve remaining dentin in the coronal two-thirds of the finished preparation.

While, OneShape is made of a conventional austenite 55- NiTi alloy with a tip size of 25 and a constant taper of 0.06 with various cross-sectional designs and variable pitch over the entire length, and is used in continuous rotation, the design is claimed to eliminate threading and binding of the instrument when working in continuous rotation.

Recently, XP Shaper instrument (FKG, LaChaux -de-faund, Switzerland) has been introduced to the market, based on the MaxWire's adaptive core technology. The MaxWire alloy allows the instrument to shift its shape from a relatively malleable and straight shape at room temperature, to a more robust shape at body temperature. The transformation cause the instrument to be flexible and straight at room temperature with high cutting efficiency at body temperature ${ }^{(5)}$.

Hence, the purpose of the study was to compare the effect of the new NiTi rotary instrument (XP
Shaper instrument) on the canal transportation and the canal centering ability with other single file NiTi instruments utilizing reciprocation motion (WaveOne) and full rotation (One shape) using cone beam computed tomography. The null hypothesis was that there is no difference among the 3 rotary NiTi file systems regarding the analyzed parameters.

\section{MATERIALS AND METHODS}

\section{Selection of the samples}

A total of forty-five human permanent mandibular first molars extracted due to periodontal or prosthodontics reasons from the Department of Oral Surgery, Cairo University were selected. Preoperative periapical radiographs were taken to inspect the mesial roots and to determine the angle of root curvature. The inclusion criteria included the presence of two canals in the mesial root with independent apical foramina, complete root formation, no internal root calcification, no internal or external root resorption, mesiobuccal canal curvatures between $20^{\circ}$ and $35^{\circ}$ according to Schneider's method ${ }^{(6)}$.

\section{Preparation of the samples}

The crowns were sectioned using a water-cooled safe sided diamond disc leaving $3 \mathrm{~mm}$ above the cemento-enamel junction. The distal roots were separated from the mesial ones using diamond discs. The presence of two separate mesial canals was confirmed by simultaneous application of two K-files \#10 (Maillefer, Ballaigus, Switzerland) in the canals. Only the mesiobuccal canals were used in instrumentation. Patency was checked and the working length was determined by subtracting 1 $\mathrm{mm}$ from the apical foramen.

The roots were vertically mounted halfway in transparent auto polymerizing acrylic resin (Acrostone, Dental \& Medical Supplies, Cairo, Egypt) mixed according to the manufacturer's instructions inside a silicon mold $(10 \mathrm{~cm} \times 10 \mathrm{~cm})$ to fix them before scanning. To prevent the resin from enter- 
ing the apical foramen, the apices of the roots were sealed with wax (Wilson, Sao Paulo, Brazil). Each sample was inserted into the unset acrylic resin so that its long axis was parallel to the long axis of the mold to ensure standardization of the specimens for tomographic imaging. To facilitate the orientation of canal during the scanning, an amalgam filling was inserted into the resin at the bucco-distal line angle of the roots.

\section{Pre-instrumentation scanning:}

All roots were scanned using cone beam computed tomography (CBCT) system (Scanora 3D, Soredex, Palodex group, Finland) at $85 \mathrm{kVp}$ and 15 $\mathrm{mA}$ to determine the canal shape before instrumentation. For each specimen, three tomograms were selected according to the distance from the root apex as follow: $3 \mathrm{~mm}$ corresponding to the apical third, $5 \mathrm{~mm}$ corresponding to the middle third and 7 $\mathrm{mm}$ corresponding to the cervical third. All images were assessed using Software program (OnDemand 3D, Cybermed, South Korea).

\section{Root Canal Preparation}

A \#15 K- file (Maillefer, Ballaigus, Switzerland) was used to establish a glide path. The samples were randomly divided into 3 equal groups $(n=15$ canals per group) as follow:

- Group I: The WaveOne group, root canals were shaped with WaveOne Primary reciprocating files using a slow in-and out pecking motion with amplitude of about $3 \mathrm{~mm}$. The flutes of the instruments were cleaned after three in-and out movements (pecks)

- Group II: The OneShape group, root canals were shaped with OneShape rotary file with the motor set to $350 \mathrm{rpm} / 5-\mathrm{Ncm}$ torque, The instrument was used in slow pecking motion with an amplitude of less than $3 \mathrm{~mm}$. The flutes of the instrument were cleaned after three in and out movements (pecks) till reaching the working length.
- Group III: The XP- Shaper group, root canals were shaped with XP-shaper file with the motor set at $900 \mathrm{rpm} / 1-\mathrm{Ncm}$ torque. The file was inserted into the canal and 5 strokes were applied till reaching the working length.

Root canal preparation was performed using $\mathrm{X}$-smart plus endodontic motor (Dentsply, Tulsa Dental, Tulsa, OK). Freshly prepared 2.6\% sodium hypochlorite solution was used as an irrigant during instrumentation procedure with a 30-gauge needle tips (NaviTip, Ultradent, South Jordan, UT, USA) $1 \mathrm{~mm}$ short from the working length.

\section{Post-instrumentation scanning:}

The root canals were scanned after the mechanical preparation using CBCT in the same pre-instrumentation scanning protocol.

The shortest distance from the periphery of the root (mesial and distal) to the edge of the mesiobuccal canal was measured by using the measure length tool on the reconstructed cross-sectional images of the pre and post-instrumentation scans

Where, M1: is the shortest distance from the mesial edge of the root to the mesial edge of the uninstrumented canal.

M2: is the shortest distance from the mesial edge of the root to the mesial edge of the instrumented canal.

D1: is the shortest distance from the distal edge of the root to the distal edge of the un-instrumented canal.

D2: is the shortest distance from the distal edge of the root to the distal edge of the instrumented canal

The degree of canal transportation was calculated according to the formula given by Gambill et al. ${ }^{(7)}$ :

Canal transportation $=(\mathrm{M} 1-\mathrm{M} 2)-(\mathrm{D} 1-\mathrm{D} 2)$

Regarding transportation direction, CT equal to 0 (zero) meant lack of transportation, a negative 
value represented transportation to the distal direction, and a positive value represented transportation toward the mesial direction.

Centering ability ratio was calculated using the values obtained during the measurement of transportation using the following equation:

Centralization ability ratio $=(\mathrm{M} 1-\mathrm{M} 2) /(\mathrm{D} 1-$ D2) or (D1-D2) /(M1-M2)

The formula was chosen in such a manner that the lowest of the results obtained through the difference should always be the numerator. A result equal to 1.0 indicated perfect centralization. When value was closer to zero, it implied that the instrument had a lower capacity to maintain itself in the central axis of the canal.

\section{Assessment of root canal preparation}

Root canal preparations were completed by one operator, while the assessment of the canal curvatures prior to and after instrumentation was carried out by a second examiner who was blind about all experimental groups.

\section{Statistical analysis}

Data were presented as mean and standard deviation (SD) values. Kruskal-Wallis test was used to compare the three systems. Friedman's test was used to compare the different root levels. Dunn's test was used for pair-wise comparisons. Fisher's Exact test was used to compare the three systems. The significance level was set at $\mathrm{P} \leq 0.05$.

\section{RESULTS}

\section{Canal Transportation}

At 3 as well as $5 \mathrm{~mm}$ level from the apex; results showed WaveOne and OneShape had highest mean amount of transportation with no statistically significant difference between them. However, Xp Shaper showed the statistically significantly lowest mean amount of transportation (Table 1).

At $7 \mathrm{~mm}$ from the apex: There was a statistically significant difference between the three groups. WaveOne showed the highest mean amount of transportation $(0.22 \pm 0.09)$ followed by OneShape $(0.14 \pm 0.11)$ followed by Xp Shaper, which had the lowest mean amount of transportation $(0.08 \pm 0.06)$.

Results showed that on using the WaveOne instrument, there was a statistically significant difference between root levels $(P$-value $=0.035)$. The highest distal transportation was found at $3 \mathrm{~mm}$ from the apex. While, the highest mesial transportation was observed at $7 \mathrm{~mm}$ level. However, OneShape and XP Shaper instruments showed no statistically significant difference among the different root levels $(P$-value $=0.061$, $P$-value $=0.175)($ table 2$)$.

TABLE (1): The mean, standard deviation (SD) values and results of Kruskal-Wallis test for comparison between canal transportation values ( $\mathrm{mm}$ ) after using the three systems

\begin{tabular}{|c|c|c|c|c|c|c|c|}
\hline \multirow{2}{*}{ Root level } & \multicolumn{2}{|c|}{ WaveOne } & \multicolumn{2}{c|}{ One Shape } & \multicolumn{2}{c|}{ XP Shaper } & \multirow{2}{*}{$P$-value } \\
\cline { 2 - 8 } & Mean & SD & Mean & SD & Mean & SD \\
\hline $3 \mathrm{~mm}$ & $0.14^{\mathrm{A}}$ & 0.10 & $0.12^{\mathrm{A}}$ & 0.16 & $0.07^{\mathrm{B}}$ & 0.06 & $0.023^{*}$ \\
\hline $5 \mathrm{~mm}$ & $0.19^{\mathrm{A}}$ & 0.13 & $0.21^{\mathrm{A}}$ & 0.15 & $0.05^{\mathrm{B}}$ & 0.04 & $0.001^{*}$ \\
\hline $7 \mathrm{~mm}$ & $0.22^{\mathrm{A}}$ & 0.09 & $0.14^{\mathrm{B}}$ & 0.11 & $0.08^{\mathrm{C}}$ & 0.06 & $0.001^{*}$ \\
\hline Total & $0.18^{\mathrm{A}}$ & 0.07 & $0.16^{\mathrm{A}}$ & 0.11 & $0.07^{\mathrm{B}}$ & 0.04 & $<0.001^{*}$ \\
\hline
\end{tabular}

*: Significant at $P \leq 0.05$, Different superscripts in the same row are statistically significantly different 
TABLE (2): The frequencies (n), percentages (\%) and results of Friedman's test for comparison between direction of transportation among different root levels

\begin{tabular}{|c|c|c|c|c|c|c|c|c|}
\hline \multirow[b]{2}{*}{ System } & \multirow[b]{2}{*}{ Direction } & \multicolumn{2}{|c|}{$3 \mathrm{~mm}$} & \multicolumn{2}{|c|}{$5 \mathrm{~mm}$} & \multicolumn{2}{|c|}{$7 \mathrm{~mm}$} & \multirow{2}{*}{$P$-value } \\
\hline & & $\mathrm{n}$ & $\%$ & $\mathrm{n}$ & $\%$ & $\mathrm{n}$ & $\%$ & \\
\hline \multirow{3}{*}{ WaveOne } & Distal & 10 & 66.7 & 6 & 40 & 2 & 13.3 & \multirow{3}{*}{$0.035^{*}$} \\
\hline & Mesial & 5 & 33.3 & 7 & 46.7 & 13 & 86.7 & \\
\hline & No transportation & 0 & 0 & 2 & 13.3 & 0 & 0 & \\
\hline \multirow{3}{*}{ One Shape } & Distal & 13 & 86.7 & 9 & 60 & 7 & 46.7 & \multirow{3}{*}{0.061} \\
\hline & Mesial & 2 & 13.3 & 6 & 40 & 8 & 53.3 & \\
\hline & No transportation & 0 & 0 & 0 & 0 & 0 & 0 & \\
\hline \multirow{3}{*}{ XP Shaper } & Distal & 8 & 53.3 & 11 & 73.3 & 6 & 40 & \multirow{3}{*}{0.175} \\
\hline & Mesial & 5 & 33.3 & 4 & 26.7 & 9 & 60 & \\
\hline & No transportation & 2 & 13.3 & 0 & 0 & 0 & 0 & \\
\hline
\end{tabular}

*: Significant at $P \leq 0.05$

\section{Centering Ability}

The maintenance of canal curvature was better with One Shape $(0.54 \pm 0.11)$ and Xp Shaper $(0.41 \pm$ $0.15)$ as compared to WaveOne, which showed the statistically significantly lowest mean centering ratio $(0.31 \pm 0.12)$ (Fig 1$)$

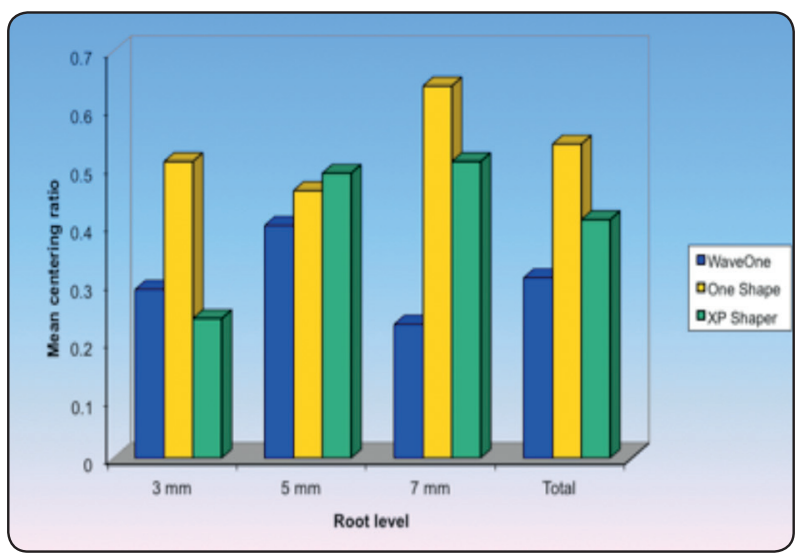

Fig. (1) Bar chart representing mean centering ratios after using the three systems
At the level of $3 \mathrm{~mm}$ from the apex; One Shape showed the highest mean statistically significant centering ratio $(0.51 \pm 0.32)$ and there was no statistically significant difference between WaveOne and XP Shaper instruments. At $5 \mathrm{~mm}$ level; there was no statistically significant difference among the three systems. Where, at $7 \mathrm{~mm}$ level; OneShape showed the statistically significantly highest mean centering ratio followed by XP Shaper followed by WaveOne.

\section{DISCUSSION}

Ever since Schilder advocates the concept of preparing the root canal in a funnel shape, while maintaining its original curve ${ }^{(8)}$; ideal cleaning and shaping of the root canal systems remains a very challenging procedure.

The American Association of Endodontists defined transportation as 'Removal of the canal wall structure on the outside curve in the apical half of the canal due to the tendency of the files to 
restore their original shape during canal preparation (9). The treatment prognosis is adversely affected by the inappropriate pattern of dentin removal as it causes high risk of straightening the original canal curvature, increase the rate of debris extrusion and postoperative discomfort ${ }^{(10)}$.

In the present study, mesiobuccal canals of extracted first mandibular molars were chosen to provide conditions similar to the clinical situation and to allow realistic evaluation of the instruments performance ${ }^{(11)}$.

It has been documented that increasing the size of the apical preparation may improve the irrigation and cleaning efficiency but lead to unnecessary dentin removal and increase the risk of canal transportation ${ }^{(12)}$. Thus, single file instruments were selected for this study.

CBCT was used as it allows detailed threedimensional (3D) observation of the root canal forms with high-resolution images, faster acquisition and reconstruction scheme. $\mathrm{CBCT}$ is effective in measuring dentin thickness, apical transportation and canal centering ${ }^{(13)}$.

Two parameters were assessed in the study: Apical transportation which can jeopardize efficient sealing of the root canal subsequently, reducing the treatment outcome and maintenance of the canal centering which is a primary requisite on preparing curved root canals ${ }^{(11)}$

Results showed that at the levels of 3 and $5 \mathrm{~mm}$ from the apex; there was no statistically significant difference between WaveOne and OneShape; both showed the highest mean amount of transportation, compared to XP Shaper. This could be attributed to the tip diameter corresponding to a size 25 for both WaveOne and the primary OneShape instrument comparable to size 17 which XP Shaper initially started with.

At the level of $7 \mathrm{~mm}$ from the apex; WaveOne showed the highest statistically significantly mean amount of transportation followed by OneShape, while the XP Shaper showed the statistically significantly lowest mean amount of transportation. There is an inverse relationship between instrument tapering and canal transportation (14). WaveOne instrument has an $8 \%$ taper over the first 3 millimeters that decreases to $4.3 \%$ and $5.5 \%$, respectively and the primary OneShape instrument has a constant $6 \%$ taper. While, XP shaper possesses initial $1 \%$ taper through its whole length which expands to a final $4 \%$ taper $^{(15,5)}$

As regards the overall canal transportation; the results of this study showed that XP Shaper showed the lowest statistically significantly mean amount of transportation, while both WaveOne and OneShape instruments showed highest mean amount of transportation with no statistically significant difference between them.

The excellent results of XP Shaper can be attributed to its Adaptive Core, where it can expand while maintaining the original canal curvature ${ }^{(5)}$. XP applies minimal stress to the dentin walls, thereby can adapt easily to the canal irregularities ${ }^{(16)}$

On the other hand, the attitude of OneShape instrument in the canal could be explained by its asymmetrical cutting edges. This design feature when combined with continuous rotation at a relatively high speed $(350 \mathrm{rpm})$ cause the instrument to progress into the curved canals, creating some stress that might result in the observed apical transportation ${ }^{(15)}$

While The results of our investigation cannot be compared directly with those of Azim et al (5) because of the different file systems used, both results are consistent, they revealed that XP Shaper was superior to Vortex Blue in terms of shaping ability, where the file created nonuniform preparation adapting to the complex canal anatomy

Our results came in agreement with Agarwal et $a l^{(17)}$ and Alrahabi and Alkady ${ }^{(18)}$, who showed no 
statistically significant difference between WaveOne and OneShape instruments in canal transportation. You et al ${ }^{(19)}$ reported similar transportation for reciprocation motion and conventional continuous rotation technique Also, Capar et al. ${ }^{(20)}$ investigated six rotary file systems (ProTaper Next, ProTaper Universal, classical OneShape, Reciproc, Twisted File Adaptive, SM2, and WaveOne) and reported no significant difference among them in terms of transportation and canal curvature.

There have been contradictory results with Saber et al. ${ }^{(15)}$ who compared WaveOne, Reciproc, and OneShape. In that study, the use of OneShape files resulted in significantly greater apical transportation than WaveOne. Also, other studies declared that WaveOne system preserved the original canal curvature better than the OneShape system ${ }^{(21,22)}$.

However, it has to be declared that Wu et al ${ }^{(23)}$ reported that apical transportation of more than 0.3 $\mathrm{mm}$ can negatively affect the sealability of filling material. In the present study none of the rotary systems used caused more than $0.2 \mathrm{~mm}$ apical transportation.

Results showed that on using the WaveOne instrument, more distal canal transportation was apparent at $3 \mathrm{~mm}$ from the apex while at $7 \mathrm{~mm}$ level, results showed higher tendency toward mesial transportation

These results confirm that as the diameter of the files increases, there is an increased tendency for canal transportation ${ }^{(10)}$ While OneShape and XP Shaper instruments showed no statistically significant difference among the different root levels. So, it can be postulated to avoid apical enlargement of curved canals with instruments of taper greater than 0.06 .

Sinai documented that aggressiveinstrumentation in the cervical third of the root canal may lead to strip perforations and subsequently inflammatory complications ${ }^{(24)}$. Less transportation towards this area can be considered a favorable feature for the Wave One and XP Shaper instruments.

Agarwal et al ${ }^{(17)}$ showed that at 3-mm above the apex ProTaper and WaveOne groups showed transportation towards the lateral side of the canal curvature while the OneShape group remained centred, which collaborate with the results of this study.

This result differs from previous studies that indicate that the apical segment usually has more canal transportation toward the outside of the curve $^{(25)}$.

Our results demonstrated that at the level of 3 $\mathrm{mm}$ from the apex; OneShape showed the highest mean statistically significant centering ratio and there was no statistically significant difference between WaveOne and XP Shaper instruments. NiTi instruments are non-aggressive by nature and exert less force on the canal walls as they need less stress to bend causing less cutting on either side ${ }^{(26)}$.

At $5 \mathrm{~mm} \mathrm{level;} \mathrm{there} \mathrm{was} \mathrm{no} \mathrm{statistically}$ significant difference among the three systems. Where at $7 \mathrm{~mm}$ level; OneShape showed the statistically significantly highest mean centering ratio followed by XP Shaper followed by WaveOne. These findings can be related to that instruments with constant taper in the apical section produce good centering ability compared to instruments with progressive tapers along the cutting surface ${ }^{(27) .}$

As regards total centering ratio; OneShape showed the statistically significantly highest mean centering ratio $(0.54 \pm 0.11)$ followed by XP Shaper $(0.41 \pm 0.15)$ followed by WaveOne $(0.31 \pm 0.12)$, which showed the statistically significantly lowest mean centering ratio. The superiority of OneShape instrument may be attributed to its design that progressively changes from variable 3 -cutting edges at the tip to an S-shaped 2 cutting edges near the shaft ${ }^{(28)}$. The snake-like motion aid to preserve the original canal shape due to the offset rotation center 
causing the file to engage and disengage along the canal wall, thus reducing the stresses between the file and the canal wall ${ }^{(18)}$.

Whereas, WaveOne instrument showed low centering ability as it is considered a relatively large rigid single file with more taper that moves apically till reaching the working length creating a piston effect ${ }^{(29)}$

The finding of this research is consistent with previous results obtained by different authors, Saleh et al ${ }^{(30)}$ who showed that canals prepared with the F360 and OneShape systems were better centered than those prepared with Reciproc and WaveOne systems. Agarwal et al ${ }^{(17)}$ showed that OneShape group had less transportation and remained more centered than WaveOne group, however the differences were not statistically significant, whereas its contradicted by those of Dhingra et $a l^{(22)}$, and Tambe et al ${ }^{(21)}$ who showed the superiority of WaveOne system over OnesShape in terms of centering ability.

\section{CONCLUSIONS}

According to the results of the present investigation, the null hypothesis was rejected because significant differences were obtained between the 3 single-file systems regarding their shaping ability, the Xp shaper represents a new generation of rotary files that can be classified as an adaptive core instrument which can expand beyond its nominal size, its small mass and expanding properties appear to better preserve the original shape of the canal than OneShape and WaveOne NiTi systems.

\section{REFERENCES:}

1. Haapasalo M, Endal U, Zandi H, Coil JM. Eradication of endodontic infection by instrumentation and irrigation solutions. Endod Topics 2005;10:77-102.

2. Gonzalez-Rodriguez MP, Ferrer-Luque CM. A comparison of ProFile, Hero 642, and K3 instrumentation systems in teeth using digital imaging analysis. Oral Surg Oral Med Oral Pathol Oral Radiol Endod 2004;97:112-5.
3. Fornari VJ, Silva-Sousa YT, Vanni JR. Histological evaluation of the effectiveness of increased apical enlargement for cleaning the apical third of curved canals. Int Endod J 2010;43:988-94.

4. da Frota MF, Filho IB, Berbert FL, et al. Cleaning capacity promoted by motor-driven or manual instrumentation using ProTaper Universal system: histological analysis. J Conserv Dent 2013;16:79-82.

5. Azim AA, Piasecki L, da Silva Neto UX, Cruz ATG and Azim KA. XP Shaper, A Novel Adaptive Core Rotary Instrument: Micro-computed Tomographic Analysis of Its Shaping Abilities. J Endod 2017 ;43(9):1532-1538.

6. Schneider SW. A comparison of canal preparations in straight and curved root canals. Oral Surg Oral Med Oral Pathol. 1971; 32(2):271-5.

7. Gambill JM, Alder M, del Rio CE. Comparison of nickeltitanium and stainless steel hand-file instrumentation using computed tomography. J Endod. 1996;22(7):369-75.

8. Schilder H. Cleaning and shaping the root canal. Dent Clin North Am. 1974;18:269-96

9. Endodontists AAo. Glossary of endodontic terms. Chicago: AAE;2003.

10. López FU, Fachin EV, Camargo Fontanella VR, Barletta FB, Só MV, Grecca FS. Apical transportation: A comparative evaluation of three root canal instrumentation techniques with three different apical diameters. J Endod. 2008;34:1545-8.

11. Hülsmann M, Peters O, Dummer PMH. Mechanical preparation of root canals. Shaping goals, techniques and means. Endod Topics. 2005;10:30-76.

12. El Ayouti A, Dima E, Judenhofer L-st C, Pichler BJ. Increased Apical Enlargement Contributes to Excessive Dentin Removal in Curved Root Canals: A Stepwise Microcomputed Tomography Study. J Endod.2011;37:1580-4.

13. Cotton TP, Geisler TM, Holden DT, Schwartz SA, Schindler WG. Endodontic applications of cone-beam volumetric tomography. J Endod. 2007;33:1121-32.

14. Pique F, Ganahl D, Peters OA. Effects of root canal preparation on apical geometry assessed by microcomputed tomography. J Endod. 2009;35:1056-9.

15. Saber SEDM, Nagy MM, Schafer E. Comparative evaluation of the shaping ability of WaveOne, Reciproc 
and OneShape single-file systems in severely curved root canals of extracted teeth. Int Endod J.2015; 48: 109- 114.

16. FKG XP Endo Shaper. Available at: http://www.fkg.ch/ sites/default/files/201607_ fkg_xps_brochure_en_web. pdf. Accessed October 25, 2016.

17. Agarwal RS, Agarwal J, Jain P, Chandra A. Comparative analysis of canal centering ability of different single file systems using cone beam computed tomography- An in vitro study. J Clin Diagn Res. 2015;9(5):ZC06-ZC10.

18. Mothanna Alrahabi, Ayman Alkady. Comparison of root canal apical transportation associated with Wave One, ProTaper Next, TF, and OneShape nickel-titanium instruments in curved canals of extracted teeth: A radiographic evaluation. Saudi J Dent Res 2017;8:1-4

19. You SY, Kim HC, Bae KS, Baek SH, Kum KY, Lee W. Shaping ability of reciprocating motion in curved root canals: A comparative study with micro-computed tomography. J Endod. 2011;37:1296-300

20. Capar ID, Ertas H, Ok E, Arslan H, Ertas ET: Comparative study of different novel nickel-titanium rotary systems for root canal preparation in severely curved root canals. J Endod 2014, 40:852-6

21. Tambe VH, Nagmode PS, Abraham S, Patait M, Lahoti PV, Jaju N. Comparison of canal transportation and centering ability of rotary ProTaper, OneShape system and Wave One system using cone beam computed tomography: an in vitro study. J Conserv Dent 2014;17:561.

22. DhingraA,Kochar R, BanerjeeS, SrivastavaP.Comparative evaluation of the canal curvature modifications after instrumentation with OneShape rotary and Wave One reciprocating files. J Conserv Dent 2014;17:138.
23. Wu MK, R'oris A, Barkis D, Wesselink PR. Prevalence and extent of long oval canals in the apical third. Oral Surg Oral Med Oral Pathol Oral Radiol Endod.2000 Jun;89(6):739-43.

24. Sinai IH. Endodontic perforations: their prognosis and treatment. J Am Dent Assoc. 1977;95(1):90-95.

25. Silva e Souza PA, Dores RS, Tartari T, Pinheiro TP, Tuji FM, Silva e Souza Jr MH. Effects of sodium hypochlorite associated with EDTA and etidronate on apical root transportation. Int Endod J. 2014 Jan;47(1):20-5.

26. Kandaswamy D, Venkateshbabu N, Porkodi I and Pradeep G. Canal-centering ability: An endodontic challenge. Department of Conservative Dentistry and Endodontics, Sri Ramachandra Dental College, Porur, Chennai - 600 116, India

27. Yang GB, Zhou XD, Zheng YL, Zhang H, Shu Y, Wu HK. Shaping ability of progressive versus constant taper instruments in curved root canals of extracted teeth. Int Endod J. 2007; 40:707-14

28. Bürklein S, Benten S, Schäfer E. Shaping ability of different single-file systems in severely curved root canals of extracted teeth. Int Endod J. 2013; 46:590-7.

29. Gambarini G, Testarelli L, De Luca M, Milana V, Plotino G, Grande NM, et al. The influence of three different instrumentation techniques on the incidence of postoperative pain after endodontic treatment. Ann Stomatol (Roma) 2013; 4:152-5

30. Saleh AM, GilaniPV, Tavanafar S and Schafer E. Shaping Ability of 4 Different Single-file Systems in Simulated S-shaped Canals. JEndod 2015;4: 548-5233. 